\title{
Total fluid and specific beverage intake and mortality due to IHD and stroke in the Netherlands Cohort Study
}

\author{
Lina J. Leurs ${ }^{1}$, Leo J. Schouten ${ }^{1}$, R. Alexandra Goldbohm ${ }^{2}$ and Piet A. van den Brandt ${ }^{1}$ \\ ${ }^{1}$ Department of Epidemiology, GROW - School for Oncology and Developmental Biology, Maastricht University, PO Box 616, \\ 6200 MD Maastricht, The Netherlands \\ ${ }^{2}$ Department of Prevention and Health, TNO Quality of Life, Leiden, The Netherlands
}

(Received 18 September 2009 - Revised 13 April 2010 - Accepted 14 April 2010 - First published online 11 May 2010)

Chronic mild dehydration has been associated with several diseases, including fatal IHD and stroke. It has been suggested that hydration through total fluid intake (or water) is inversely associated with IHD or stroke mortality. The objective of the present study was to evaluate the relationship between total fluid (and specific beverage) intake and IHD or stroke mortality in the Netherlands Cohort Study (NLCS). In 1986, 120 852 participants aged 55-69 years were enrolled into the NLCS. Mortality data were collected over a 10-year follow-up period. Analysis was done through a case-cohort approach, and it was based on the subjects without a history of heart disease, stroke or diabetes at baseline. A total of 1789 IHD mortality cases and 708 stroke mortality cases occurred during the follow-up. Higher total fluid consumption was not associated with either IHD mortality or stroke mortality in men or women. When analysing specific beverages, a positive association between coffee consumption (increment $270 \mathrm{ml} / \mathrm{d}$ ) and IHD mortality was observed in men (hazard ratio (HR) 1.09, $95 \%$ CI 1.00, 1.18), while an inverse relationship was observed in women (HR: 0.88, $95 \%$ CI 0.78, 1.00). For tea consumption (increment of $253 \mathrm{ml} / \mathrm{d}$ ), an inverse relationship with IHD mortality was observed in men (HR: $0.91,95 \%$ CI 0.83, 1.00). No association with water intake was observed. In the study population, fresh water consumption was very low. In conclusion, total fluid intake was not associated with IHD or stroke mortality in either men or women. Coffee consumption was inversely associated with IHD mortality in women only, while a higher tea intake was associated with lower IHD mortality in men only.

Beverage intake: Ischaemic heart disease: Stroke: Mortality: Prospective cohort studies

Proper hydration is necessary for the body to sustain normal physiological functioning such as the transportation of nutrients, excretion and the regulation of body temperature. Chronic mild to moderate dehydration has been associated with several disease states, such as fatal CHD and $\mathrm{CVD}^{(1)}$. The association between chronic mild dehydration and CHD may be explained by the elevation in haemorheological factors $^{(2,3)}$. Haemorheological factors that are independently positively associated with CHD are the whole-blood viscosity, plasma viscosity, fibrinogen and haematocrit levels ${ }^{(4-8)}$. These factors respond acutely to changes in hydration, which can occur, e.g. during normal daily activities and the use of medications such as diuretics ${ }^{(9-12)}$. Furthermore, it has been suggested that water consumption at night can attenuate nocturnal increase in blood viscosity, and therefore, can prevent morning occurrence of cerebral infarction ${ }^{(9)}$. Some investigators reported a decrease in blood viscosity with increased water intake $e^{(9,13,14)}$, while others reported no changes in blood haemorheology and chemistry with increased water intake ${ }^{(15)}$.

Only one cohort study analysed the effect of water intake and other fluid intake on fatal $\mathrm{CHD}^{(1)}$. The above-mentioned study, which was done by Chan et al., found a protective effect of water intake on mortality related to CHD in men but not in women. In contrast, a high intake of 'fluids other than water' was associated with an increased mortality risk in women but not in men. The authors explained these findings by the typically lower blood viscosity (lower haematocrit levels, erythrocyte rigidity and aggregability at all shear rates) in women ${ }^{(7)}$. Because of the lower blood viscosity, women experience less reduction in plasma volume with dehydration, and body temperature regulation occurs at lower sweat rates ${ }^{(16,17)}$. Thus, in women, reduced water intake does not produce high levels of blood viscosity as in men, which would explain why water intake is not protective in women. Because of the fact that men have larger blood volumes than women, the same quantities of hyperosmolar fluids or caffeinated beverages produce a lower proportionate decrease in intravascular volume and subsequently smaller increase in blood viscosity, explaining why 'fluids other than water' have smaller effects on CHD mortality in men ${ }^{(18-20)}$.

The effect of other beverages such as coffee and tea on IHD or stroke mortality has also been reported previously in the literature, but inconsistent results were obtained. A metaanalysis of twenty-one prospective cohort studies found a positive association between coffee and IHD in men, while coffee drinking was associated with a lower risk of IHD in women ${ }^{(21)}$. 
Also, the effect of tea intake on IHD mortality has been reported to be either inverse, no association, or even positive ${ }^{(22-27)}$.

The lack of sufficient evidence on the relationship between total fluid and other beverage intake and mortality related to IHD or stroke led to the investigation of this association in the Netherlands Cohort Study (NLCS). Due to the detailed collection on dietary and drinking habits in the NLCS, we were able to analyse the association between total fluid (and specific beverage) intake and IHD and stroke mortality, with the possibility of adjustment for potential confounding factors.

\section{Methods}

\section{Study population}

In September 1986, the population-based prospective NLCS on diet and cancer was started. In this cohort study, 58279 men and 62573 women aged between 55 and 69 years living throughout the Netherlands were included ${ }^{(28)}$. Because of efficiency reasons, a case-cohort approach was used for data processing and statistical analysis ${ }^{(29,30)}$. In a casecohort design, cases are collected from the entire cohort, while detailed follow-up information of a random subcohort provides an estimate of the person-time experience of the cohort. In the NLCS, this subcohort consisted of 5000 cohort members extracted randomly from the entire study population immediately after baseline. The subcohort was followed up biennially for vital status information. Only two male subcohort members were lost to follow-up during the 10 -year follow-up period. The study design has been described in detail previously ${ }^{(28)}$. The NLCS was approved by the institutional review boards of the Maastricht University and the Netherlands Organization for Applied Scientific Research. All cohort members consented to participate in the study by completing a mailed, self-administered questionnaire.

\section{Data collection}

All the 120852 cohort members completed a self-administered questionnaire on dietary habits, beverage consumption, anthropometry and other risk factors related to cancer and CVD at baseline ${ }^{(28)}$. Habitual consumption of food and beverages during the year preceding the start of the study was assessed using a 150-item semi-quantitative food frequency section of the questionnaire. Validation of this questionnaire was done against a $9 \mathrm{~d}$ diet record ${ }^{(31)}$. The Spearman correlation coefficient between mean daily intake of non-alcoholic beverages assessed by the questionnaire and that estimated from the $9 \mathrm{~d}$ diet record was 0.63 . The Spearman correlation coefficient between mean daily intake of alcoholic beverages assessed by the questionnaire and that estimated from the $9 \mathrm{~d}$ diet record was $0 \cdot 89^{(31)}$. Specific nutrient intakes were calculated from this section of the questionnaire using the computerised Dutch food composition table ${ }^{(32)}$. Nutrient intake was adjusted for energy intake using the residual method ${ }^{(33)}$.

\section{Assessment of total fluid and specific beverage intake}

Of the 150 FFQ items, twenty-four addressed beverage consumption. The questionnaire covered almost all beverages consumed regularly, namely water (tap or bottled), milk (i.e. milk, buttermilk, cocoa), juice (i.e. tomato, orange, others), soda and lemonade (i.e. cola, others), alcoholic beverages (i.e. beer, red wine, white wine, sherry, port, liqueur, spirits), soup, coffee and tea. The amount of beverages consumed was measured in household units (glasses, cups, soup plates, etc.). The participants could indicate the frequency of beverage consumption and the portion size. During the validation study, the capacity of the household units was measured by a dietitian who visited the subjects ${ }^{(31)}$. The standardised size of a glass measured $175 \mathrm{ml}$, a cup (coffee or tea) $125 \mathrm{ml}$ and a soup plate $250 \mathrm{ml}$. Based on the questionnaire data, the total fluid consumption was calculated using information on frequency and beverage-specific serving size of all the specific beverages. When subjects reported of drinking a specific beverage but did not report the number of units, a default number was used based on the mean number reported by the other drinkers.

\section{Ascertainment of cases}

Follow-up for mortality data was established by linkage of the NLCS to the central bureau of genealogy. Using this record linkage, 18091 deaths were identified between January 1987 and December 1996. On the basis of the collected subcohort data on vital status, it could be estimated that the Central Bureau of Genealogy linkage was complete for $99 \%$. The causes of death, coded in international classification of diseases (ICD)-9 until December 1995 and in ICD-10 from January 1996, were obtained by the linkage to Statistics Netherlands. Using this linkage, the cause of death was obtained for $18045(99.7 \%)$ of the 18091 deceased. The primary cause of death was related to CHD (ICD-9 code $390-459 /$ ICD-10 code I00-I99) in $37.2 \%$ ( $n 6735)$ of all deaths. In the present analysis, CHD-related mortality was analysed as death due to IHD (ICD-9 code 410-414/ICD-10 code I20-I25, $n 3610$ ) or CVD (stroke) (ICD-9 code 430435/ICD-10 code I60-I69, $n$ 1204).

\section{Statistical analysis}

Analysis was confined to participants who did not report physician-diagnosed heart disease, stroke or diabetes as indicated in the baseline questionnaire (exclusion of 3066 subjects). Additionally, subjects with incomplete or inconsistent dietary data ( $n$ 1010) were excluded from the analysis, leaving 1789 IHD mortality cases, 708 stroke cases and 3970 subcohort members available for the analysis. For categorical analysis, the lowest consumption stratum was chosen as the reference category. Because different associations between consumption of water and fluids other than water and cardiovascular mortality for males and females have been reported in the literature, we conducted all the analyses separately for men and women ${ }^{(1)}$. For each sex, the hazard ratios (HR) and the corresponding 95\% CI were calculated by means of a Cox proportional hazards model. The proportional hazards assumption was tested using the scaled Schoenfeld residuals ${ }^{(34)}$. When this test indicated that the assumption was violated, the $-\ln (-\ln )$ survival plots were used to assess the proportional hazards assumption. Standard errors were estimated using the robust Huber-White sandwich 
Table 1. Descriptive analysis of potential confounders of subcohort members and cases of IHD- and stroke-related mortality, Netherlands Cohort Study, 1987-96

(Mean values with their standard errors, number, percentages and ranges)

\begin{tabular}{|c|c|c|c|c|c|c|c|c|c|c|c|c|c|c|c|c|c|c|}
\hline \multirow[b]{2}{*}{ Characteristics } & \multicolumn{3}{|c|}{ Subcohort ( $n$ 1840) } & \multicolumn{3}{|c|}{ IHD mortality ( $n 1252)$} & \multicolumn{3}{|c|}{ Stroke mortality $(n 417)$} & \multicolumn{3}{|c|}{ Subcohort ( $n$ 2130) } & \multicolumn{3}{|c|}{ IHD mortality ( $n 537)$} & \multicolumn{3}{|c|}{ Stroke mortality ( $n$ 291) } \\
\hline & $\begin{array}{l}\text { Mean } \\
\text { or } n\end{array}$ & $\begin{array}{l}\mathrm{SE} \\
\text { or } \%\end{array}$ & Range & $\begin{array}{l}\text { Mean } \\
\text { or } n\end{array}$ & $\begin{array}{l}\mathrm{SE} \\
\text { or } \%\end{array}$ & Range & $\begin{array}{l}\text { Mean } \\
\text { or } n\end{array}$ & $\begin{array}{l}\text { SE } \\
\text { or } \%\end{array}$ & Range & $\begin{array}{l}\text { Mean } \\
\text { or } n\end{array}$ & $\begin{array}{l}\text { SE } \\
\text { or } \%\end{array}$ & Range & $\begin{array}{l}\text { Mean } \\
\text { or } n\end{array}$ & $\begin{array}{l}\text { SE } \\
\text { or } \%\end{array}$ & Range & $\begin{array}{l}\text { Mean } \\
\text { or } n\end{array}$ & $\begin{array}{l}\text { SE } \\
\text { or } \%\end{array}$ & Range \\
\hline \multicolumn{19}{|l|}{ Volume of total fluid intake } \\
\hline from beverages $(\mathrm{ml} / \mathrm{d})$ & $1461 \cdot 8$ & $10 \cdot 6$ & $55 \cdot 5-4688 \cdot 8$ & $1445 \cdot 2$ & $13 \cdot 1$ & $329 \cdot 7-3905 \cdot 3$ & 1438.5 & 10.5 & $74 \cdot 6-4529 \cdot 3$ & 1340.6 & 8.7 & $122-3486 \cdot 3$ & $1353 \cdot 1$ & $20 \cdot 4$ & $348 \cdot 2-4286 \cdot 9$ & $1316 \cdot 9$ & $23 \cdot 8$ & $370 \cdot 6-2782 \cdot 6$ \\
\hline Water intake & $82 \cdot 2$ & 3.8 & $0-2592 \cdot 9$ & 82.8 & 4.4 & $0-1620.5$ & 78.5 & 6.7 & $0-972 \cdot 3$ & 108.9 & 3.9 & $0-1620.5$ & $108 \cdot 2$ & $7 \cdot 2$ & $0-972 \cdot 3$ & 98.2 & 9.5 & $0-1296 \cdot 4$ \\
\hline Fluids other than water & 1379.7 & $10 \cdot 1$ & $24 \cdot 7-4202 \cdot 6$ & 1362.4 & $12 \cdot 6$ & $162 \cdot 8-3843.0$ & 1359.5 & 22.9 & $74 \cdot 6-4417 \cdot 1$ & $1231 \cdot 7$ & 8.0 & $122-3093 \cdot 7$ & $1244 \cdot 8$ & $19 \cdot 0$ & $191 \cdot 8-4286 \cdot 9$ & $1218 \cdot 7$ & $23 \cdot 1$ & $208 \cdot 2-2782 \cdot 6$ \\
\hline Coffee & 580.8 & 6.7 & $0-3750 \cdot 0$ & $600 \cdot 4$ & 8.6 & $0-2500$ & 570.5 & $6 \cdot 7$ & $0-1500$ & 497.8 & 5.4 & $0-1875$ & 487.1 & $12 \cdot 9$ & $0-2500$ & 483.0 & 15.5 & $0-1250$ \\
\hline Tea & 318.8 & 5.6 & $0-1875.0$ & 304.5 & $7 \cdot 3$ & $0-3000$ & 333.0 & $12 \cdot 3$ & $0-1250$ & 383.7 & 5.6 & $0-1875$ & $399 \cdot 3$ & $12 \cdot 6$ & $0-2500$ & 388.6 & $16 \cdot 7$ & $0-2500$ \\
\hline Milk & $186 \cdot 6$ & 4.2 & $0-1153 \cdot 7$ & 184.2 & $5 \cdot 2$ & $0-1370 \cdot 5$ & 169.8 & 8.5 & $0-1156 \cdot 6$ & $180 \cdot 6$ & 3.5 & $0-1423 \cdot 7$ & $187 \cdot 3$ & 8.8 & $0-2825 \cdot 2$ & $182 \cdot 1$ & $9 \cdot 3$ & $0-886 \cdot 6$ \\
\hline Soft drinks (coke, ...) & 41.5 & 1.8 & $0-648 \cdot 2$ & 42.5 & $2 \cdot 4$ & $0-860 \cdot 2$ & 40.7 & 4.2 & $0-835 \cdot 2$ & 30.8 & 1.4 & $0-698 \cdot 1$ & $31 \cdot 2$ & 2.6 & $0-349 \cdot 4$ & 32.5 & 3.7 & $0-486 \cdot 2$ \\
\hline Juices (orange, & & & & & & & & & & & & & & & & & & \\
\hline tomato, ...) & $22 \cdot 7$ & $1 \cdot 1$ & $0-558.4$ & 21.8 & 1.4 & $0-696 \cdot 1$ & $21 \cdot 3$ & $2 \cdot 3$ & $0-648 \cdot 2$ & 31.9 & 1.3 & $0-648 \cdot 2$ & $33 \cdot 6$ & 2.5 & $0-518.6$ & 34.6 & $4 \cdot 0$ & $0-777.9$ \\
\hline Soup & 77.7 & $2 \cdot 2$ & $0-764 \cdot 0$ & 74.7 & 2.5 & $0-555.6$ & 78.8 & 4.6 & $0-583.4$ & $60 \cdot 2$ & 1.6 & $0-750.1$ & $63 \cdot 0$ & 3.6 & $0-649.5$ & $62 \cdot 3$ & 4.8 & $0-555.6$ \\
\hline Alcoholic beverages & 151.5 & 5 & $0-2249.5$ & $134 \cdot 2$ & $5 \cdot 7$ & $0-1947 \cdot 2$ & $145 \cdot 3$ & $10 \cdot 9$ & $0-2225.5$ & $46 \cdot 7$ & 1.8 & $0-804.8$ & $43 \cdot 3$ & 6.0 & $0-2592 \cdot 1$ & 35.4 & 4.3 & $0-448$ \\
\hline Age (years) & 61.4 & 0.1 & & 63.1 & 0.1 & & 63.9 & 0.2 & & 61.6 & 0.1 & & 63.9 & 0.2 & & 63.8 & 0.2 & \\
\hline Current smoker (yes) & 67.8 & $36 \cdot 9$ & & 638 & $51 \cdot 0$ & & 196 & $47 \cdot 1$ & & 461 & $21 \cdot 6$ & & 165 & 30.7 & & 82 & $28 \cdot 3$ & \\
\hline $\begin{array}{l}\text { Number of cigarettes } \\
\text { smoked per day }\end{array}$ & $16 \cdot 2$ & 0.3 & & $16 \cdot 0$ & 0.3 & & $16 \cdot 7$ & 0.8 & & $13 \cdot 1$ & 0.4 & & $15 \cdot 8$ & 0.7 & & $15 \cdot 4$ & 0.9 & \\
\hline Years of active smoking & $41 \cdot 4$ & 0.3 & & 43.6 & 0.3 & & 43.4 & 0.7 & & 34.0 & 0.5 & & 36.0 & 0.8 & & 37.7 & 0.9 & \\
\hline Former smoker (yes) & 916 & 49.8 & & 505 & $40 \cdot 3$ & & 180 & $43 \cdot 2$ & & 441 & $20 \cdot 7$ & & 97 & $18 \cdot 1$ & & 42 & 14.4 & \\
\hline Never smoked (yes) & 246 & 13.4 & & 109 & 8.7 & & 40 & $9 \cdot 6$ & & 1228 & 57.6 & & 275 & $51 \cdot 2$ & & 166 & $57 \cdot 0$ & \\
\hline Hypertension (yes) & 388 & $21 \cdot 1$ & & 425 & 34.0 & & 158 & 37.9 & & 585 & 27.5 & & 266 & 49.5 & & 131 & $45 \cdot 0$ & \\
\hline \multicolumn{19}{|l|}{ BMI categories $\left(\mathrm{kg} / \mathrm{m}^{2}\right)$} \\
\hline$<18.5$ & 9 & 0.5 & & 10 & 0.8 & & 3 & 0.8 & & 29 & 1.4 & & 4 & 0.8 & & 5 & 1.8 & \\
\hline $18 \cdot 5-25$ & 953 & 53.7 & & 608 & $50 \cdot 2$ & & 217 & 54.9 & & 1138 & $55 \cdot 1$ & & 239 & $45 \cdot 8$ & & 155 & $56 \cdot 2$ & \\
\hline $25-30$ & 747 & $42 \cdot 1$ & & 517 & 42.7 & & 158 & $40 \cdot 0$ & & 721 & 34.9 & & 219 & $42 \cdot 0$ & & 94 & $34 \cdot 1$ & \\
\hline $30-49$ & 65 & 3.7 & & 75 & $6 \cdot 2$ & & 17 & $4 \cdot 3$ & & 178 & 8.6 & & 60 & 11.5 & & 22 & 8.0 & \\
\hline \multicolumn{19}{|l|}{$\begin{array}{l}\text { Non-occupational } \\
\text { physical activity }\end{array}$} \\
\hline Very little & 276 & $15 \cdot 2$ & & 245 & 19.7 & & 94 & $22 \cdot 8$ & & 557 & $26 \cdot 5$ & & 184 & $35 \cdot 2$ & & 95 & 33.3 & \\
\hline Average & 550 & 30.2 & & 366 & 29.4 & & 129 & 31.3 & & 739 & $35 \cdot 2$ & & 189 & $36 \cdot 2$ & & 113 & 39.6 & \\
\hline Active & 619 & 34.0 & & 411 & 33.1 & & 117 & 28.4 & & 575 & $27 \cdot 3$ & & 115 & $22 \cdot 0$ & & 52 & $18 \cdot 2$ & \\
\hline Very active & 373 & 20.5 & & 221 & 17.8 & & 72 & 17.5 & & 231 & 11.0 & & 34 & 6.5 & & 25 & 8.8 & \\
\hline \multicolumn{19}{|l|}{ Educational level } \\
\hline Primary school & 458 & 24.9 & & 359 & 28.7 & & 119 & 28.5 & & 680 & 31.9 & & 218 & $40 \cdot 6$ & & 115 & 39.5 & \\
\hline Lower vocational & 378 & 20.5 & & 230 & $18 \cdot 4$ & & 79 & 18.9 & & 500 & 30.5 & & 125 & $23 \cdot 3$ & & 63 & $21 \cdot 6$ & \\
\hline High school (junior or & & & & & & & & & & & & & & & & & & \\
\hline senior) & 637 & 34.6 & & 449 & 35.9 & & 146 & $35 \cdot 0$ & & 746 & 35.0 & & 149 & $27 \cdot 7$ & & 88 & $30 \cdot 2$ & \\
\hline Higher vocational or & & & & & & & & & & & & & & & & & & \\
\hline University & 359 & 19.5 & & 203 & $16 \cdot 2$ & & 70 & $16 \cdot 8$ & & 193 & $9 \cdot 1$ & & 39 & $7 \cdot 3$ & & 23 & 7.9 & \\
\hline \multicolumn{19}{|l|}{ Total alcohol intake $(\mathrm{g} / \mathrm{d})$} \\
\hline 0 & 248 & 13.6 & & 226 & 18.3 & & 62 & $15 \cdot 1$ & & 638 & 31.3 & & 178 & $36 \cdot 0$ & & 114 & $42 \cdot 2$ & \\
\hline $0.1-4$ & 381 & 20.9 & & 270 & 21.9 & & 97 & $23 \cdot 6$ & & 742 & $36 \cdot 4$ & & 190 & 38.4 & & 91 & 33.7 & \\
\hline $5-14$ & 504 & $27 \cdot 7$ & & 318 & 25.8 & & 86 & 20.9 & & 393 & $19 \cdot 3$ & & 65 & $13 \cdot 1$ & & 35 & $13 \cdot 0$ & \\
\hline $15-29$ & 412 & $22 \cdot 6$ & & 248 & $20 \cdot 1$ & & 89 & 21.6 & & 188 & $9 \cdot 2$ & & 43 & $8 \cdot 7$ & & 19 & 7.0 & \\
\hline$\geq 30$ & 212 & $15 \cdot 1$ & & 170 & 13.8 & & 77 & $18 \cdot 7$ & & 75 & 3.7 & & 19 & 3.8 & & 11 & 4.1 & \\
\hline \multicolumn{19}{|l|}{ Use of diuretic } \\
\hline medication (yes) & 132 & $7 \cdot 2$ & & 175 & 14.0 & & 57 & $13 \cdot 7$ & & 274 & $12 \cdot 9$ & & 127 & 23.6 & & 59 & $20 \cdot 3$ & \\
\hline \multicolumn{19}{|l|}{ Use of vitamin } \\
\hline supplements (yes) & 417 & $22 \cdot 7$ & & 264 & $21 \cdot 1$ & & 99 & $23 \cdot 7$ & & 780 & 36.6 & & 175 & 32.6 & & 98 & 33.7 & \\
\hline Total fat intake $(\mathrm{g} / \mathrm{d})$ & 94.2 & 0.3 & & 93.8 & 0.4 & & 93.1 & 0.7 & & 74.0 & 0.2 & & 74.7 & 0.5 & & $73 \cdot 2$ & 0.7 & \\
\hline Saturated fat intake & 37.1 & 0.2 & & 36.9 & 0.2 & & 36.9 & 0.4 & & 29.9 & 0.1 & & 30.0 & 0.3 & & 29.7 & 0.4 & \\
\hline
\end{tabular}


estimator to account for additional variance introduced by sampling a subcohort from the total cohort ${ }^{(35)}$.

The multivariable regression models included the following variables: age at baseline (years), sex (if applicable), cigarette smoking (current, frequency and duration) and energy intake $(\mathrm{kcal} / \mathrm{d})$. The following variables were considered as potential confounders (other known IHD risk factors or factors influencing total fluid consumption), but were not included in the models because they did not change the HR by $>5 \%$ : hypertension (yes/no), BMI $\left(\mathrm{kg} / \mathrm{m}^{2}\right)$, physical inactivity (coded in four categories: very little, average, active or very active), educational level (coded as primary school, lower vocational, high school (junior and senior) and higher vocational/university), fat consumption $(\mathrm{g} / \mathrm{d})$, fruit and vegetable consumption $(\mathrm{g} / \mathrm{d})$, hormone-replacement therapy (yes/no) (for women only), use of diuretics (yes/no) and multivitamin intake (yes/no)).

When separate beverages were analysed, a second model was used with additional correction for the intake of fluids other than the analysed beverage (e.g. analysis for coffee was corrected for the intake of beverages other than coffee). In none of the beverage-specific analyses did this additional correction with other beverage intake change the HR of the first model. Also, additional adjustment for the ethanol compound of alcoholic beverages (coded in categories 0 , $0 \cdot 1-4,5-14,15-29 \mathrm{~g} / \mathrm{d}, \geq 30 \mathrm{~g} / \mathrm{d}$ ) did not change any of the reported HR substantially. Therefore, only the results of the first model are presented in this report.

When the intake of beverages was analysed as a continuous variable, the HR was calculated per one standard deviation increment (calculated for men and women together). Tests for trends were assessed by fitting the ordinal exposure variables as continuous terms. A two-sided $P$ value of 0.05 or less was considered as statistically significant.

\section{Results}

During the 10-year follow-up period, 1789 deaths primarily related to IHD have been reported. Of these deaths, 1252 (70.0\%) occurred in the male population, and 537 (30.0\%) occurred in the female population. Stroke mortality occurred in 708 subjects, of which, $417(58.9 \%)$ were males and $291(41.1 \%)$ were females.

The mean daily total fluid consumption from beverages was $1462 \mathrm{ml} / \mathrm{d}$ in the male subcohort, and $1341 \mathrm{ml} / \mathrm{d}$ in the female subcohort (Table 1). The major beverages consumed in the male and female subcohorts were coffee (mean 581 and $498 \mathrm{ml} / \mathrm{d}$, respectively), tea (mean 319 and $384 \mathrm{ml} / \mathrm{d}$, respectively) and milk (mean 187 and $181 \mathrm{ml} / \mathrm{d}$, respectively). Only a very little amount of the daily total fluid intake was in the form of water consumption (mean $82 \mathrm{ml} / \mathrm{d}$ in men and $109 \mathrm{ml} / \mathrm{d}$ in women). Potential confounders in the present analyses are also described in Table 1. Compared with the subcohort members, subjects who suffered from fatal IHD or stroke were more often smokers, hypertensive, and less physically active.

\section{Total fluid consumption}

When analysing total fluid consumption on a continuous scale with an increment of 431 (1 SD) ml/d, no association between 
total fluid and water intake and IHD or stroke mortality was found in either men or women (see Tables 2 and 3).

Categorisation of total fluid consumption revealed that $41 \%$ of the male and $30 \%$ of the female subcohort members consumed the recommended daily dose of total fluids (at least 1.5 litres total fluid per d). It was revealed that $38 \%$ of the male subjects and $31 \%$ of the female subjects who suffered from fatal IHD, and $39 \%$ males and $28 \%$ females who died of stroke had drunk at least 1.5 litres of total fluids. Drinking at least 1.5 litres of total fluids was not related to IHD or stroke mortality compared with drinking less than the recommended daily dose in men or women. Also, analysis over five total fluid categories did not reveal an association between total fluid intake and IHD mortality in men or women. HR for the association between total fluid intake and stroke mortality were all below 1 , but were not statistically significant.

Total fluid intake (consumption of at least $1.5 v .<1.5$ litres) was not associated with IHD and stroke mortality across different subgroups of the population defined by risk factors for CVD (sex, smoking, hypertension and BMI) (Table 4).

\section{Specific beverage consumption}

In men, a positive association between increasing coffee intake and IHD mortality was observed (HR per increment of 1 SD: $1 \cdot 09,95 \%$ CI $1.00,1 \cdot 18)$, while an inverse relationship between increasing tea consumption (increment of $1 \mathrm{SD}$ ) and IHD mortality was observed (HR: 0.91, $95 \% \mathrm{CI}$ $0.83,1.00$ ) (Table 2). In women, an inverse association between coffee consumption (increment of $1 \mathrm{SD}$ ) and IHD mortality was observed (HR: 0.88, $95 \%$ CI 0.78, 1.00), while a positive (not statistically significant) relationship between increasing tea consumption (increment of $1 \mathrm{SD}$ ) and IHD mortality was observed (HR: $1.08,95 \%$ CI $0.97,1.20$ ). No relationship was observed between milk, soft drink, juice, soup and alcoholic beverage consumption and IHD mortality. When the endpoint was stroke mortality, no associations with separate beverages were observed (Table 3), except for the intake of alcoholic beverages in females. In females, intake of alcoholic beverages (per $1 \mathrm{SD}$ or $166 \mathrm{ml} / \mathrm{d}$ ) was inversely associated with stroke mortality (HR: 0.66, $95 \%$ CI 0.44, 0.97).

We analysed the observed relationship between coffee and tea intake and IHD mortality more detailedly using categorical variables for these beverages. In the categorical analysis, the positive association between coffee consumption and IHD mortality in men was not statistically significant. For tea, we observed that all categories of tea intakes (moderate (1-2 cups/d) and high tea consumption ( $>3$ cups/d)) were inversely related to IHD mortality in men (HR: 0.75 ; $95 \%$ CI $0.61,0.93$ and HR: $0.71,95 \%$ CI $0.57,0 \cdot 88$, respectively $(P$-trend $=0.007))$ compared with $0-1 \mathrm{cup} / \mathrm{d}$ of tea consumption (Table 2).

In women, a more detailed analysis of coffee consumption revealed an inverse dose-response relationship with IHD mortality $(P$-trend $=0.01)$. In the categorical analysis, the positive association between tea consumption and IHD mortality in women was no longer significant.

The association between coffee and tea consumption categories and IHD and stroke mortality was relatively consistent across different subgroups of the population defined by risk factors for CVD (sex, smoking, hypertension and BMI) (data not shown).

Water as such was not consumed by $53 \%$ of the male and $43 \%$ of the female subcohort members, $57 \%$ of the males and $45 \%$ of the females who died of IHD and $56 \%$ of males and $46 \%$ of the females who died of stroke. In men, drinking any water compared with drinking no water at all was not statistically significantly associated with a reduced risk of IHD mortality (HR: $0.87,95 \%$ CI $0.74,1.03$ ) in the multivariate analysis. In women, drinking any water compared with drinking no water at all was not associated with IHD mortality (HR: 0.92 , $95 \%$ CI $0.75,1.11$ ). When stroke mortality was the endpoint, no significant association with water consumption was observed in men or women. When analysing water in five categories, we observed a decreased HR of IHD mortality for male subjects who consumed between $>0$ and $100 \mathrm{ml}$ water a day compared with those consuming no water (HR: 0.69, $95 \%$ CI 0.55, 0.87). With the other water categories also, no relationship was observed ( $P$-trend $=0 \cdot 68)$. Also, when stroke mortality was the outcome measure, no relationship between any of the five water categories was observed in men. In women, no relationship between any of the five water categories and IHD or stroke mortality was observed.

\section{Discussion}

We found no overall association between total fluid intake and IHD or stroke mortality in either men or women. However, a positive association between coffee consumption and IHD mortality was observed in men, while the opposite (inverse association between coffee intake and IHD mortality) was observed in women. For tea consumption, we observed an inverse relationship with IHD mortality in the male subjects, but not in the female subjects. In women, except for the intake of alcoholic beverages, no associations were observed when stroke mortality was the outcome measure.

We observed that a higher coffee consumption was statistically significantly associated with lower IHD mortality in women, while the opposite was observed in men. These opposite results are in line with the results of a meta-analysis of twenty-one prospective cohort studies ${ }^{(36)}$. The reason for this sex difference, however, is unknown. Apart from a direct effect of coffee consumption on IHD mortality, it is also known that coffee consumption is strongly associated with smoking. Smoking is often associated with unhealthier lifestyle habits (e.g. physical inactivity, alcohol abuse) compared with non-smoking ${ }^{(36)}$. We adjusted for inter alia smoking in our multivariate analysis - and this changed the HR estimates in women substantially - but adjustment for these factors may not have completely eliminated their influence on the coffeeIHD association, and therefore, may partially explain the observed sex differences. The positive association between IHD and coffee consumption in men has also been reported in previous studies ${ }^{(37-40)}$. In the meta-analysis done by $\mathrm{Wu}$ et al., the 1 pooled HR for males with heavy (5-6 cups/d) and very heavy ( $\geq 7 \mathrm{cups} / \mathrm{d}$ ) coffee consumption (HR: 1.07, $95 \%$ CI $0.91,1.26$ and HR: $1.15,95 \%$ CI $0.91,1.46)$ were slightly elevated, but they did not reach statistical significance $^{(36)}$. The positive association between coffee consumption and IHD can be explained by diterpenes cafestol and 
Table 2. Association of the different fluid consumptions and IHD mortality in the Netherlands Cohort Study, 1987-96 (Hazard ratios (HR) and $95 \%$ confidence intervals)

\begin{tabular}{|c|c|c|c|c|c|c|c|c|c|c|}
\hline & \multicolumn{5}{|c|}{ Males } & \multicolumn{5}{|c|}{ Females } \\
\hline & \multirow[b]{2}{*}{$\begin{array}{c}n \text { cases } / n \\
\text { person-years }\end{array}$} & \multicolumn{2}{|c|}{$\begin{array}{l}\text { Age-adjusted } \\
\text { analyses }\end{array}$} & \multicolumn{2}{|c|}{$\begin{array}{l}\text { Multivariate } \\
\text { analyses }\end{array}$} & \multirow[b]{2}{*}{$\begin{array}{c}n \text { cases } / n \\
\text { person-years }\end{array}$} & \multicolumn{2}{|c|}{$\begin{array}{l}\text { Age-adjusted } \\
\text { analyses }\end{array}$} & \multicolumn{2}{|c|}{$\begin{array}{l}\text { Multivariate } \\
\text { analyses }\end{array}$} \\
\hline & & $\mathrm{HR}$ & $95 \% \mathrm{Cl}^{*}$ & $\mathrm{HR}$ & $95 \% \mathrm{Cl} \dagger$ & & HR & $95 \% \mathrm{Cl}^{*}$ & HR & $95 \% \mathrm{Cl} \dagger$ \\
\hline \multicolumn{11}{|l|}{ Total fluid intake, categories (ml/d) } \\
\hline $0-1000$ & $176 / 2069$ & 1.00 & Reference & 1.00 & Reference & $123 / 3803$ & 1.00 & Reference & 1.00 & Reference \\
\hline$>1000-1250$ & $279 / 3609$ & 0.96 & $0.74,1.25$ & 0.92 & $0.70,1 \cdot 22$ & $121 / 4667$ & 0.84 & $0.63,1.13$ & 0.82 & $0.60,1 \cdot 10$ \\
\hline$>1250-1500$ & $320 / 4374$ & 0.95 & $0.74,1 \cdot 22$ & 0.99 & $0 \cdot 75,1 \cdot 30$ & $124 / 5869$ & 0.70 & $0.53,0.94$ & 0.66 & $0.49,0.88$ \\
\hline$>1500-2000$ & $342 / 5139$ & 0.87 & $0.68,1 \cdot 11$ & 0.90 & $0.69,1 \cdot 19$ & $124 / 4781$ & 0.89 & $0.66,1.19$ & 0.82 & $0 \cdot 60,1 \cdot 13$ \\
\hline$>2000$ & $135 / 1784$ & 1.02 & $0.75,1.13$ & 1.03 & $0.73,1.47$ & 45/1201 & $1 \cdot 33$ & $0.88,2 \cdot 01$ & 1.04 & $0.67,1.61$ \\
\hline$P$-trend & & 0.54 & & 0.91 & & & $0.84 \ddagger$ & & $0.46 \ddagger$ & \\
\hline \multicolumn{11}{|l|}{ Daily recommended fluid consumption (ml/d) } \\
\hline$<1500$ & $775 / 10053$ & 1.00 & Reference & 1.00 & Reference & $368 / 14329$ & 1.00 & Reference & 1.00 & Reference \\
\hline$\geq 1500$ & $477 / 6922$ & 0.94 & $0.81,1.09$ & 0.96 & $0.81,1 \cdot 14$ & $169 / 5992$ & $1 \cdot 17$ & $0.95,1.45$ & $1 \cdot 10$ & $0 \cdot 88,1 \cdot 38$ \\
\hline Total fluid (per $1 \mathrm{SD}$ increment $=430.58 \mathrm{ml}$ ) & $1252 / 16976$ & 1.00 & $0.93,1.07$ & 1.01 & $0.93,1 \cdot 10$ & $537 / 20321$ & $1 \cdot 08 \ddagger$ & $0.96,1.22$ & $1.02 \ddagger$ & $0.90,1 \cdot 15$ \\
\hline \multicolumn{11}{|l|}{ Water, categories $(\mathrm{ml} / \mathrm{d})$} \\
\hline 0 & $712 / 8953$ & 1.00 & Reference & 1.00 & Reference & $243 / 8740$ & 1.00 & Reference & 1.00 & Reference \\
\hline$>0-100$ & $170 / 3080$ & 0.70 & $0.57,0.87$ & 0.69 & $0.55,0.87$ & $81 / 3899$ & 0.75 & $0.57,1.00$ & 0.80 & $0.60,1.06$ \\
\hline$>100-200$ & $208 / 3014$ & 0.84 & $0.68,1.03$ & 0.87 & $0.69,1.08$ & $128 / 4482$ & 1.05 & $0.82,1.35$ & 1.06 & $0.82,1.38$ \\
\hline$>200-500$ & $135 / 1612$ & 1.09 & $0.84,1.41$ & $1 \cdot 20$ & $0.92,1.58$ & $69 / 2584$ & 0.98 & $0.72,1.34$ & 0.91 & $0.66,1.25$ \\
\hline$>500$ & $27 / 316$ & 1.20 & $0.69,2.07$ & $1 \cdot 33$ & $0.76,2 \cdot 36$ & $16 / 616$ & 0.94 & $0.52,1.69$ & 0.70 & $0.37,1.34$ \\
\hline$P$-trend & & 0.79 & & $0.68 \ddagger$ & & & 0.90 & & 0.56 & \\
\hline \multicolumn{11}{|l|}{ No $v$. any water consumption (ml/d) } \\
\hline 0 & $712 / 8953$ & 1.00 & Reference & 1.00 & Reference & $243 / 8740$ & 1.00 & Reference & 1.00 & Reference \\
\hline$>0$ & $540 / 8022$ & 0.85 & $0.73,0.99$ & 0.87 & $0.74,1.03$ & $294 / 11581$ & 0.93 & $0.76,1 \cdot 13$ & 0.92 & $0 \cdot 75,1 \cdot 12$ \\
\hline Water intake (per 1 SD increment $=171.44 \mathrm{ml}$ ) & $1252 / 16976$ & 1.01 & $0.94,1.08$ & $1.04 \ddagger$ & $0.96,1 \cdot 12$ & $537 / 20321$ & 1.00 & $0.92,1 \cdot 10$ & 0.96 & $0.87,1.06$ \\
\hline \multicolumn{11}{|l|}{ Coffee, categories (cups/d) } \\
\hline $0-2 \S$ & 189/2609 & 1.00 & Reference & 1.00 & Reference & $142 / 4087$ & 1.00 & Reference & 1.00 & Reference \\
\hline$>2-4$ & $451 / 6441$ & 0.98 & $0.78,1 \cdot 23$ & 0.91 & $0.71,1 \cdot 16$ & $237 / 9640$ & 0.79 & $0.62,1.01$ & 0.75 & $0.58,0.97$ \\
\hline$>3-6$ & $413 / 5553$ & 1.18 & $0.93,1.49$ & 1.02 & $0.79,1.31$ & $113 / 5197$ & 0.74 & $0.56,0.99$ & 0.62 & $0.46,0.84$ \\
\hline$>6$ & 199/2372 & 1.44 & $1.10,1.90$ & $1 \cdot 17$ & $0.86,1.59$ & $45 / 1397$ & $1 \cdot 17$ & $0.78,1.76$ & 0.71 & $0.45,1 \cdot 12$ \\
\hline$P$-trend & & 0.002 & & 0.17 & & & $0.58 \ddagger$ & & 0.01 & \\
\hline Coffee $($ per 1 SD increment $=269.96 \mathrm{ml})$ & $1252 / 16976$ & $1 \cdot 15$ & $1 \cdot 07,1.24$ & 1.09 & $1 \cdot 00,1 \cdot 18$ & $537 / 20321$ & $1 \cdot 02 \ddagger$ & $0.89,1 \cdot 16$ & 0.88 & $0.78,1.00$ \\
\hline \multicolumn{11}{|l|}{ Tea, categories (cups/d) } \\
\hline $0-1 \S$ & $429 / 5041$ & 1.00 & Reference & 1.00 & Reference & $114 / 4268$ & 1.00 & Reference & 1.00 & Reference \\
\hline$>1-2$ & $301 / 4422$ & 0.72 & $0.59,0.88$ & 0.75 & $0.61,0.93$ & $111 / 4592$ & 0.94 & $0.69,1.27$ & 1.07 & $0.79,1.47$ \\
\hline$>2-3$ & $180 / 2382$ & 0.78 & $0.61,0.99$ & 0.89 & $0.69,1 \cdot 15$ & $87 / 3435$ & 0.87 & $0.63,1.20$ & 1.03 & $0.73,1.44$ \\
\hline$>3$ & $342 / 5131$ & 0.61 & $0.50,0.75$ & 0.71 & $0.57,0.88$ & $225 / 8026$ & 0.94 & $0.73,1.23$ & $1 \cdot 13$ & $0.85,1.49$ \\
\hline$P$-trend & & $<0.001$ & & 0.007 & & & 0.71 & & 0.44 & \\
\hline Tea $($ per $1 \mathrm{SD}$ increment $=253.45 \mathrm{ml}$ ) & $1252 / 16976$ & 0.85 & $0.78,0.94$ & 0.91 & $0.83,1.00$ & $537 / 20321$ & 1.02 & $0.92,1.13$ & 1.08 & $0.97,1.20$ \\
\hline
\end{tabular}

Adjusted for age.

Adjusted for age, current smoking, number of cigarettes smoked, years of active smoking and total energy intake (kcal).

This $P$ or HR has to be interpreted with care, because the categorical analysis shows a strong U-shaped association.

$\S$ One cup $=125 \mathrm{ml}$. 
Table 3. Association of the different fluid consumptions and stroke mortality in the Netherlands Cohort Study, 1987-96

\begin{tabular}{|c|c|c|c|c|c|c|c|c|c|c|}
\hline & \multicolumn{5}{|c|}{ Males } & \multicolumn{5}{|c|}{ Females } \\
\hline & \multirow[b]{2}{*}{$\begin{array}{c}n \text { cases } / n \\
\text { person-years }\end{array}$} & \multicolumn{2}{|c|}{$\begin{array}{l}\text { Age-adjusted } \\
\text { analyses }\end{array}$} & \multicolumn{2}{|c|}{$\begin{array}{l}\text { Multivariate } \\
\text { analyses }\end{array}$} & \multirow[b]{2}{*}{$\begin{array}{c}n \text { cases } / n \\
\text { person-years }\end{array}$} & \multicolumn{2}{|c|}{$\begin{array}{l}\text { Age-adjusted } \\
\text { analyses }\end{array}$} & \multicolumn{2}{|c|}{$\begin{array}{l}\text { Multivariate } \\
\text { analyses }\end{array}$} \\
\hline & & HR & $95 \% \mathrm{Cl}^{*}$ & $\mathrm{HR}$ & $95 \% \mathrm{Cl} \dagger$ & & HR & $95 \% \mathrm{Cl}^{*}$ & HR & $95 \% \mathrm{Cl} \dagger$ \\
\hline \multicolumn{11}{|l|}{ Total fluid intake, categories (ml/d) } \\
\hline $0-1000$ & $64 / 2069$ & 1.00 & Reference & 1.00 & Reference & $65 / 3803$ & 1.00 & Reference & 1.00 & Reference \\
\hline$>1000-1250$ & $92 / 3610$ & 0.88 & $0.61,1.28$ & 0.93 & $0.63,1.38$ & $62 / 4667$ & $0 \cdot 81$ & $0.56,1 \cdot 19$ & 0.80 & $0.54,1.17$ \\
\hline$>1250-1500$ & 99/4374 & 0.83 & $0.57,1.20$ & 0.84 & $0.57,1.25$ & $82 / 5869$ & 0.88 & $0.62,1 \cdot 26$ & 0.80 & $0.56,1 \cdot 16$ \\
\hline$>1500-2000$ & $124 / 5139$ & 0.89 & $0.63,1.27$ & 0.89 & $0.60,1.30$ & $68 / 4781$ & 0.92 & $0.64,1.33$ & 0.78 & $0.52,1 \cdot 15$ \\
\hline$>2000$ & $38 / 1784$ & 0.82 & $0.52,1.30$ & 0.77 & $0.45,1.30$ & $14 / 1201$ & 0.78 & $0.42,1.44$ & 0.60 & $0.31,1 \cdot 15$ \\
\hline$P$-trend & & 0.50 & & 0.35 & & & 0.64 & & 0.13 & \\
\hline \multicolumn{11}{|l|}{ Daily recommended fluid consumption $(\mathrm{ml} / \mathrm{d})$} \\
\hline$<1500$ & $255 / 10053$ & 1.00 & Reference & 1.00 & Reference & 209/14329 & 1.00 & Reference & 1.00 & Reference \\
\hline$\geq 1500$ & $162 / 6922$ & 0.99 & $0.79,1 \cdot 24$ & 0.95 & $0 \cdot 74,1 \cdot 22$ & $82 / 5992$ & 1.00 & $0 \cdot 76,1 \cdot 31$ & 0.87 & $0.65,1.17$ \\
\hline Total fluid $($ per $1 \mathrm{SD}$ increment $=430.58 \mathrm{ml}$ ) & $417 / 16976$ & 0.99 & $0 \cdot 88,1 \cdot 11$ & 0.98 & $0 \cdot 86,1 \cdot 11$ & $291 / 20321$ & 0.98 & $0.85,1 \cdot 13$ & 0.89 & $0.77,1.04$ \\
\hline \multicolumn{11}{|l|}{ Water, categories $(\mathrm{ml} / \mathrm{d})$} \\
\hline 0 & $233 / 8953$ & 1.00 & Reference & 1.00 & Reference & $135 / 8740$ & 1.00 & Reference & 1.00 & Reference \\
\hline$>0-100$ & 60/3080 & 0.76 & $0.55,1.05$ & 0.80 & $0.57,1.11$ & 47/3899 & 0.78 & $0.55,1 \cdot 12$ & 0.84 & $0.59,1.20$ \\
\hline$>100-200$ & 72/3014 & 0.88 & $0.65,1.19$ & 0.89 & $0.64,1.23$ & $70 / 4482$ & 1.05 & $0.76,1.43$ & 1.06 & $0.77,1.46$ \\
\hline$>200-500$ & $46 / 1612$ & $1 \cdot 16$ & $0.80,1.67$ & 1.23 & $0.83,1.81$ & $33 / 2584$ & 0.84 & $0.56,1.27$ & 0.79 & $0.52,1.21$ \\
\hline$>500$ & 6/316 & 0.84 & $0.33,2.11$ & 0.85 & $0.31,2 \cdot 29$ & 6/616 & 0.63 & $0.27,1.51$ & 0.49 & $0.19,1.24$ \\
\hline$P$-trend & & 0.88 & & 0.93 & & & 0.43 & & 0.23 & \\
\hline \multicolumn{11}{|l|}{ No $v$. any water consumption (ml/d) } \\
\hline 0 & $233 / 8953$ & 1.00 & Reference & 1.00 & Reference & $135 / 8740$ & 1.00 & Reference & 1.00 & Reference \\
\hline$>0$ & $184 / 8022$ & 0.88 & $0.71,1 \cdot 11$ & 0.91 & $0.72,1.16$ & $156 / 11581$ & 0.89 & $0.70,1.14$ & 0.89 & $0.69,1 \cdot 15$ \\
\hline Water intake $($ per 1 SD increment $=171.44 \mathrm{ml})$ & $417 / 16976$ & 0.98 & $0.89,1.08$ & 1.00 & $0 \cdot 89,1 \cdot 11$ & $291 / 20321$ & 0.95 & $0.84,1.08$ & 0.91 & $0.80,1.03$ \\
\hline \multicolumn{11}{|l|}{ Coffee, categories (cups/d) } \\
\hline $0-2 \ddagger$ & $74 / 2609$ & 1.00 & Reference & 1.00 & Reference & $77 / 4087$ & 1.00 & Reference & 1.00 & Reference \\
\hline$>2-4$ & $164 / 6441$ & 0.90 & $0.66,1.25$ & 0.84 & $0 \cdot 60,1 \cdot 18$ & $126 / 9640$ & 0.77 & $0.56,1.04$ & 0.79 & $0.57,1.09$ \\
\hline$>3-6$ & $110 / 5553$ & 0.83 & $0.59,1.17$ & 0.72 & $0.50,1.04$ & $60 / 5197$ & 0.72 & $0.50,1.04$ & 0.70 & $0.48,1.02$ \\
\hline$>6$ & 69/2372 & 1.38 & $0.93,2.05$ & $1 \cdot 15$ & $0.74,1.77$ & 28/1397 & $1 \cdot 37$ & $0.85,2.22$ & $1 \cdot 10$ & $0.63,1.90$ \\
\hline P-trend & & 0.30 & & $0.95 \S$ & & & $0.96 \S$ & & $0.50 \S$ & \\
\hline Coffee $($ per 1 SD increment $=269.96 \mathrm{ml})$ & $417 / 16976$ & 1.07 & $0.96,1 \cdot 20$ & $1 \cdot 01 \S$ & $0.89,1.14$ & $291 / 20321$ & $1.00 \S$ & $0.86,1 \cdot 17$ & $0.94 \S$ & $0 \cdot 80,1 \cdot 10$ \\
\hline \multicolumn{11}{|l|}{ Tea, categories (cups/d) } \\
\hline $0-1 \ddagger$ & $114 / 5041$ & 1.00 & Reference & 1.00 & Reference & $62 / 4268$ & 1.00 & Reference & 1.00 & Reference \\
\hline$>1-2$ & $107 / 4422$ & 0.92 & $0.68,1.25$ & 0.96 & $0.70,1.32$ & $62 / 4592$ & 0.95 & $0.65,1.39$ & 1.04 & $0.70,1.55$ \\
\hline$>2-3$ & $61 / 2382$ & 0.95 & $0.66,1.35$ & 0.98 & $0.66,1.44$ & 48/3435 & 0.88 & $0.58,1.32$ & 1.04 & $0.68,1.60$ \\
\hline$>3$ & $135 / 5131$ & 0.84 & $0.63,1.12$ & 0.95 & $0.70,1 \cdot 29$ & $119 / 8026$ & 0.91 & $0.65,1.27$ & 1.02 & $0.71,1.46$ \\
\hline P-trend & & 0.27 & & 0.77 & & & 0.58 & & 0.95 & \\
\hline Tea $($ per $1 \mathrm{SD}$ increment $=253.45 \mathrm{ml})$ & $417 / 16976$ & 0.94 & $0.83,1.07$ & 0.99 & $0.87,1.12$ & $291 / 20321$ & 0.98 & $0.85,1.12$ & 0.98 & $0.86,1 \cdot 11$ \\
\hline
\end{tabular}

${ }^{*}$ Adjusted for age.

$\dagger$ Adjusted for age, current smoking, number of cigarettes smoked, years of active smoking and total energy intake (kcal).

$\ddagger$ One cup $=125 \mathrm{ml}$.

$\S$ This $P$ or HR has to be interpreted with care, because the categorical analysis shows a strong U-shaped association. 
Table 4. Analyses for the detection of potential effect modification (Hazard ratios (HR) and $95 \%$ confidence intervals)*

\begin{tabular}{|c|c|c|c|c|c|c|}
\hline \multirow{3}{*}{$\begin{array}{l}\text { Risk factor } \\
\text { for CVD }\end{array}$} & \multicolumn{3}{|c|}{ IHD mortality } & \multicolumn{3}{|c|}{ Stroke mortality } \\
\hline & \multicolumn{2}{|c|}{$\begin{array}{c}\text { Consumption of } \\
\geq 1.5 \text { litres beverages } \\
v .<1.5 \text { litres }\end{array}$} & \multirow{2}{*}{$\begin{array}{c}P \text { interaction } \\
\text { test }\end{array}$} & \multicolumn{2}{|c|}{$\begin{array}{c}\text { Consumption of } \\
\geq 1.5 \text { litres beverages } \\
v .<1.5 \text { litres }\end{array}$} & \multirow{2}{*}{$\begin{array}{c}P \text { interaction } \\
\text { test }\end{array}$} \\
\hline & $\mathrm{HR}$ & $95 \% \mathrm{Cl} \dagger$ & & $\mathrm{HR}$ & $95 \% \mathrm{Cl} \dagger$ & \\
\hline \multicolumn{7}{|l|}{ Sex } \\
\hline Women & $1 \cdot 10$ & $0.88,1.38$ & & 0.87 & $0.65,1.17$ & \\
\hline Men & 0.96 & $0.81,1 \cdot 14$ & 0.24 & 0.95 & $0.74,1.22$ & 0.92 \\
\hline \multicolumn{7}{|l|}{ Smoking } \\
\hline Never/past & 0.97 & $0.81,1 \cdot 16$ & & 0.93 & $0.73,1.19$ & \\
\hline Present & 1.03 & $0.83,1.29$ & 0.35 & 0.90 & $0.67,1.22$ & 0.82 \\
\hline \multicolumn{7}{|l|}{ Hypertension } \\
\hline No & 0.98 & $0.83,1.17$ & & 0.90 & $0.71,1.15$ & \\
\hline Yes & 1.04 & $0.81,1.33$ & 0.81 & 0.96 & $0.70,1.32$ & 0.87 \\
\hline \multicolumn{7}{|l|}{ BMI $\left(\mathrm{kg} / \mathrm{m}^{2}\right)$} \\
\hline$<18.5$ & \multicolumn{2}{|c|}{ Insufficient cases } & & \multicolumn{2}{|c|}{ Insufficient cases } & \\
\hline $18 \cdot 5-25$ & 0.98 & $0.80,1.21$ & & 0.92 & $0.70,1.20$ & \\
\hline $25-30$ & 1.00 & $0.81,1 \cdot 24$ & & 0.99 & $0.72,1.35$ & \\
\hline$>30$ & 1.63 & $0.90,2.96$ & 0.73 & 1.40 & $0.61,3 \cdot 22$ & 0.81 \\
\hline
\end{tabular}

kahweol that are present in unfiltered coffee ${ }^{(41-43)}$. Cafestol and kahweol are potent cholesterol-elevating compounds present in coffee, which are independently associated with the risk of $\mathrm{CVD}^{(44,45)}$. However, in the Netherlands, mainly filtered coffee is consumed, in which the concentration of these diterpenes is very low and not associated with the elevated risk of IHD.

Tea consumption was inversely associated with IHD mortality in the male study population. The potential beneficial effect of tea on IHD has been reported previously ${ }^{(39-41)}$. However, other studies found no association or even a positive association between tea intake and IHD mortality ${ }^{(25-27)}$ Our analysis also suggests a sex difference for the association between tea intake and IHD mortality, but not as clearly as has been suggested for coffee. As mentioned in the previous section, the observed opposite effect could partially be explained by the fact that we have not been able to remove all the confounding effects ${ }^{(27)}$. We observed that when coffee and tea consumptions were included together in the multivariate analyses, the HR did not change substantially. The intriguing differences between the sexes observed for both coffee and tea indicate that further investigation of the responsible compounds and the biological mechanisms involved has to be done.

The effect of water intake on fatal CHD was analysed in only one other study ${ }^{(1)}$. In contrast to the study done by Chan et al., we found no association between the intake of water and fluids other than water and mortality related to IHD. The reason for us not finding an association could be the marked differences in drinking habits between the present study population and the population analysed by Chan et al. The average water consumption in the Adventist population was approximately $1000 \mathrm{ml} / \mathrm{d}$, while it was approximately $95 \mathrm{ml} / \mathrm{d}$ in the NLCS population. The reported total fluid intake from beverages was around 2 litres/d in the Adventist population, and was 1.4 litres/d in the present study population. Another possible reason for the different results is that in these observational studies, the results have been biased by confounding. Subjects who drink more water could be more health conscious, e.g. drinking more water may be a marker of higher physical activity ${ }^{(1)}$. We corrected for potential confounders such as physical activity in the multivariate analyses. Diabetics, who may drink more fluids, and are at increased risk of IHD and stroke, were excluded from these analyses. Furthermore, the null association was relatively consistent across subgroups of the population.

The strengths of the present study include the relatively large number of cases in a prospective cohort; the ability to examine the intake of total fluid and specific beverages in relation to the risk of IHD and stoke mortality due to the broad data collection on commonly consumed beverages (including water); the possibility to control for a broad spectrum of confounders such as age, cigarette smoking, hypertension and the intake of other fluids besides the one under investigation.

One disadvantage of the present study is the low consumption of fresh water. Of the male and female subcohort members, 53 and $43 \%$, respectively, reported that they did not consume any fresh water at all. Another disadvantage is that when subjects reported of drinking a specific beverage but did not report the number of units, a default number was used based on the mean number reported by the other drinkers. This could lead to reduction of the variance of the variable. However, this occurred in only a limited number of participants.

In conclusion, total fluid intake was not associated with IHD- or stroke-related mortality in either men or women in 
the NLCS. Coffee consumption was inversely associated with IHD mortality in women and it was positively associated with it in men, while tea consumption was inversely associated with IHD mortality in men, but not in women.

\section{Acknowledgements}

None of the authors has a financial or personal conflict of interest. This manuscript has been read by all the authors who accept responsibility for its contents. L. J. L. participated in all the processes of the present research topic. L. J. S. assisted with the statistical analysis. L. J. S. and P. A. v. d. B. contributed to writing of the manuscript and R. A. G. contributed to the refining of the manuscript. The present study was funded by KWR, Watercycle Research Institute. This project was conducted within the Joint Research Programme of the Dutch water companies by researchers from the Maastricht University and Kiwa Water Research. External review of the design and results was conducted by a Scientific Advisory Committee consisting of Professor P. Hunter (University of East Anglia, Norwich, United Kingdom), Professor R. Rylander (Emeritus Professor, Sweden) and M.I. Sinclair (Water Quality Research Australia Limited, Monash University, Australia). The authors are much indebted for their valuable comments and, in addition, would like to thank Margreet Mons for initiating this project and for her involvement in the design and advice. They also thank A. Volovics and A. Kester for statistical advice; S. van de Crommert, H. Brants, J. Nelissen, C. de Zwart, M. Moll, W. van Dijk and A. Pisters for assistance; and $H$. van Montfort, T. van Moergastel, L. van den Bosch, R. Schmeitz and J. Berben for programming assistance. Furthermore, they are indebted to all the participants of the present study and the Dutch Central Bureau of Genealogy and Statistics Netherlands for data provision.

\section{References}

1. Chan J, Knutsen SF, Blix GG, et al. (2002) Water, other fluids, and fatal coronary heart disease: the Adventist Health Study. Am J Epidemiol 155, 827-833.

2. Dvilansky A, Bar-Am J, Nathan I, et al. (1979) Hematologic values in healthy older people in the Negev area. Isr J Med Sci 15, 821-825.

3. Kristal-Boneh E, Glusman JG, Chaemovitz C, et al. (1988) Improved thermoregulation caused by forced water intake in human desert dwellers. Eur J Appl Physiol Occup Physiol 57, $220-224$

4. Lowe GD, Lee AJ, Rumley A, et al. (1997) Blood viscosity and risk of cardiovascular events: the Edinburgh Artery Study. $\mathrm{Br} \mathrm{J}$ Haematol 96, 168-173.

5. Koenig W, Sund M, Filipiak B, et al. (1998) Plasma viscosity and the risk of coronary heart disease: results from the MONICA - Augsburg Cohort Study, 1984 to 1992. Arterioscler Thromb Vasc Biol 18, 768-772.

6. Ernst E (1995) Haematocrit and cardiovascular risk. J Intern Med 237, 527-528.

7. de Simone G, Devereux RB, Chien S, et al. (1990) Relation of blood viscosity to demographic and physiologic variables and to cardiovascular risk factors in apparently normal adults. Circulation 81, 107-117.
8. Erikssen G, Thaulow E, Sandvik L, et al. (1993) Haematocrit: a predictor of cardiovascular mortality? J Intern Med 234, 493-499.

9. Kurabayashi H, Kubota K, Tamura J, et al. (1991) A glass of water at midnight for possible prevention of cerebral infarction. Stroke 22, 1326-1327.

10. Seaman GV, Engel R, Swank RL, et al. (1965) Circadian periodicity in some physicochemical parameters of circulating blood. Nature 207, 833-835.

11. Vandewalle H, Lacombe C, Lelievre JC, et al. (1988) Blood viscosity after a 1-h submaximal exercise with and without drinking. Int J Sports Med 9, 104-107.

12. Yasaka M, Yamaguchi T, Oita J, et al. (1993) Clinical features of recurrent embolization in acute cardioembolic stroke. Stroke 24, 1681-1685.

13. Okamura K, Washimi Y, Endo H, et al. (2005) Can high fluid intake prevent cerebral and myocardial infarction? [Systematic review]. Nippon Ronen Igakkai Zasshi 42, 557-563.

14. Wood JH (1987) Response to the editor: is the circadian change in hematocrit and blood viscosity a factor triggering cerebral and myocardial infarction? Stroke 18, 813.

15. Tonstad S, Klemsdal TO, Landaas S, et al. (2006) No effect of increased water intake on blood viscosity and cardiovascular risk factors. Br J Nutr 96, 993-996.

16. Byrd R, Stewart L, Torranin C, et al. (1977) Sex differences in response to hypohydration. J Sports Med Phys Fitness 17, 65-68.

17. Rocker L, Kirsch K, Stoboy H, et al. (1977) The influence of heat stress on plasma volume and intravascular proteins in sedentary females. Eur J Appl Physiol Occup Physiol 36, 187-192.

18. Neuhauser B, Beine S, Verwied SC, et al. (1997) Coffee consumption and total body water homeostasis as measured by fluid balance and bioelectrical impedance analysis. Ann Nutr Metab 41, 29-36.

19. Bell S, Anderson F, Bistrian B, et al. (1987) Osmolality of beverages commonly provided on clear and full liquid menu. Nutr Clin Pract 2, 241-244.

20. Bhalla A, Sankaralingam S, Dundas R, et al. (2000) Influence of raised plasma osmolality on clinical outcome after acute stroke. Stroke 31, 2043-2048.

21. Wu JN, Ho SC, Zhou C, et al. (2009) Coffee consumption and risk of coronary heart diseases: a meta-analysis of 21 prospective cohort studies. Int J Cardiol 137, 216-225.

22. Geleijnse JM, Launer LJ, Hofman A, et al. (1999) Tea flavonoids may protect against atherosclerosis: the Rotterdam Study. Arch Intern Med 159, 2170-2174.

23. Sesso HD, Gaziano JM, Buring JE, et al. (1999) Coffee and tea intake and the risk of myocardial infarction. Am J Epidemiol 149, $162-167$.

24. Arts IC, Hollman PC, Feskens EJ, et al. (2001) Catechin intake might explain the inverse relation between tea consumption and ischemic heart disease: the Zutphen Elderly Study. Am J Clin Nutr 74, 227-232.

25. Klatsky AL, Armstrong MA \& Friedman GD (1993) Coffee, tea, and mortality. Ann Epidemiol 3, 375-381.

26. Hertog MG, Sweetnam PM, Fehily AM, et al. (1997) Antioxidant flavonols and ischemic heart disease in a Welsh population of men: the Caerphilly Study. Am J Clin Nutr 65, 1489-1494.

27. Woodward M \& Tunstall-Pedoe H (1999) Coffee and tea consumption in the Scottish Heart Health Study follow up: conflicting relations with coronary risk factors, coronary disease, and all cause mortality. J Epidemiol Community Health 53, 481-487.

28. van den Brandt PA, Goldbohm RA, van't Veer P, et al. (1990) A large-scale prospective cohort study on diet and cancer in The Netherlands. J Clin Epidemiol 43, 285-295. 
29. Prentice RA (1986) A case-cohort design for epidemiologic cohort studies and disease prevention trials. Biometrika 73,1-11.

30. Wacholder S, Gail M \& Pee D (1991) Selecting an efficient design for assessing exposure-disease relationships in an assembled cohort. Biometrics 47, 63-76.

31. Goldbohm RA, van den Brandt PA, Brants HA, et al. (1994) Validation of a dietary questionnaire used in a large-scale prospective cohort study on diet and cancer. Eur J Clin Nutr 48, 253-265.

32. Nevo-table (1986) Nederlands voedingsstoffenbestand 1986-1987 (Dutch Food Composition Table 1986-1987). The Hague: Voorlichtingsbureau voor de Voeding.

33. Willett W \& Stampfer MJ (1986) Total energy intake: implications for epidemiologic analyses. Am J Epidemiol 124, $17-27$.

34. Schoenfeld D (1982) Partial residuals for the proportional hazards regression model. Biometrika 69, 239-241.

35. Lin D \& Wei LJ (1989) The robust inference for the Cox proportional hazards model. J Am Stat Assoc 84, 1074-1078.

36. LeGrady D, Dyer AR, Shekelle RB, et al. (1987) Coffee consumption and mortality in the Chicago Western Electric Company Study. Am J Epidemiol 126, 803-812.

37. Rosengren A \& Wilhelmsen L (1991) Coffee, coronary heart disease and mortality in middle-aged Swedish men: findings from the Primary Prevention Study. J Intern Med 230, 67-71.
38. Lindsted KD, Kuzma JW \& Anderson JL (1992) Coffee consumption and cause-specific mortality. Association with age at death and compression of mortality. J Clin Epidemiol 45, 733-742.

39. Klag MJ, Mead LA, LaCroix AZ, et al. (1994) Coffee intake and coronary heart disease. Ann Epidemiol 4, 425-433.

40. Urgert R \& Katan MB (1996) The cholesterol-raising factor from coffee beans. J R Soc Med 89, 618-623.

41. Weusten-Van der Wouw MP, Katan MB, Viani R, et al. (1994) Identity of the cholesterol-raising factor from boiled coffee and its effects on liver function enzymes. J Lipid Res $\mathbf{3 5}$ $721-733$

42. Heckers H, Gobel U \& Kleppel U (1994) End of the coffee mystery: diterpene alcohols raise serum low-density lipoprotein cholesterol and triglyceride levels. J Intern Med 235, 192-193.

43. Tverdal A, Stensvold I, Solvoll K, et al. (1990) Coffee consumption and death from coronary heart disease in middle aged Norwegian men and women. Br Med J 300, 566-569.

44. Hammar N, Andersson T, Alfredsson L, et al. (2003) Association of boiled and filtered coffee with incidence of first nonfatal myocardial infarction: the SHEEP and the VHEEP study. J Intern Med 253, 653-659.

45. Coats A (2009) Ethical authorship and publishing. Int J Cardiol 131, 149-150. 